\title{
Chronic exposure to the gibberellin derivative GA-13315 sensitizes breast cancer MCF-7 cells but not colon cancer HCT116 cells to irinotecan
}

\author{
XIANLIANG CHENG, GUOHUI WANG, YUAN LIAO, JIAO MO and CHEN QING \\ School of Pharmaceutical Science and Yunnan Key Laboratory of Pharmacology for Natural Products, \\ Kunming Medical University, Kunming, Yunnan 650500, P.R. China
}

Received September 21, 2019; Accepted July 20, 2020

DOI: $10.3892 / \mathrm{ol} .2020 .12144$

\begin{abstract}
Chlorine-3,15-dioxy-gibberellic acid methyl ester (GA-13315) is a gibberellin derivative that exhibits selective cytotoxicity to multidrug resistant MCF-7/ADR cells and reverses drug resistance when administered at subtoxic doses in combination with chemotherapy drugs. The present study aimed to investigate the impact of chronic GA-13315 exposure on the chemosensitivity of MCF-7 and HCT116 cell lines. Cells were administered a subtoxic dose of $1 \mu \mathrm{M}$ GA-13315 for 12 weeks and the sensitivity of the cells to GA-13315, irinotecan and cisplatin, was assessed. The Cell Counting Kit- 8 assay results demonstrated that the chronic exposure did not induce resistance to GA-13315, in either MCF-7 or HCT116 cells. Notably, MCF-7 cells were sensitized to irinotecan following exposure to GA-13315; however, HCT116 cells were not. The sensitizing effect of GA-13315 was associated with the alterations of topoisomerase 1 (Top1) protein expression, tyrosyl DNA phosphodiesterase 1 and checkpoint kinase 1 . Further analysis indicated that GA-13315 caused DNA fragmentation; however, DNA damage was not mediated by a Top1-dependent molecular mechanism, as GA-13315 was revealed not to be a Top1 poison, despite inhibiting the catalytic activity of Top1. Taken together, the results of the present study indicated that GA-13315 may be used for sensitizing MCF-7 cells to irinotecan, as the chronic exposure of GA-13315 to MCF-7 cells still showed sensitizing effects to irinotecan.
\end{abstract}

Correspondence to: Dr Jiao Mo or Professor Chen Qing, School of Pharmaceutical Science and Yunnan Key Laboratory of Pharmacology for Natural Products, Kunming Medical University, 1168 West Chunrong Road, Kunming, Yunnan 650500, P.R. China

E-mail:mojiao@kmmu.edu.cn

E-mail: qingchen@kmmu.edu.cn

Abbreviations: ABC, adenosine triphosphate-binding cassette; Top1, topoisomerase I; Tdp1, tyrosyl DNA phosphodiesterase 1; Chk1, checkpoint kinase 1

Key words: topoisomerase I, chronic exposure, chemosensitivity, multidrug resistance

\section{Introduction}

Topoisomerase 1 (Top1) poisons, including camptothecin (CPT), irinotecan (CPT-11), and topotecan comprise a major component of the conventional chemotherapy drugs that are used for the treatment of cancer in developing countries due to low costs and ease of access $(1,2)$. However, the therapeutic efficacy of conventional chemotherapy drugs is attenuated by the multidrug resistance that malignant tumor cells develop against structurally and mechanistically varied chemotherapeutic drugs upon exposure to a single agent $(3,4)$. In order to overcome multidrug resistance or at least delay its occurrence, conventional chemotherapy drugs are sequentially used or combined with other forms of therapies, such as immunotherapy and radiotherapy, in clinical practice $(5,6)$. The combination of conventional agents with a small molecule compound that essentially reverses multidrug resistance or increases the chemosensitivity of tumor cells has been proposed as a promising therapeutic approach $(3,4)$. For example, overexpression of adenosine triphosphate-binding cassette $(\mathrm{ABC})$ transporter proteins induced by tumor cells has been validated as an important molecular mechanism of multidrug resistance (7-9). Currently, molecules that target certain ABC transporters, such as verapamil, biricodar (VX-710) and elacridar (GF120918), are under investigation in an attempt to discover candidates for combined therapy (10); however, these molecules are yet to prove effective and safe enough for clinical application (9).

Gibberellins are commonly used to regulate plant growth and are commercially available in large quantities $(11,12)$. 13-Chlorine-3,15-dioxy-gibberellic acid methyl ester (GA-13315) is a gibberellin derivative that exhibits an antitumor effect in vivo (13); its chemical structure is presented in Fig. 1.

GA-13315 exhibits a stronger cytotoxicity to the multidrug-resistant human breast carcinoma MCF-7/ADR cell line, which overexpresses ABCB1 transporter proteins, than to the sensitive parental MCF-7 cell line. GA-13315 is able to sensitize the resistant MCF-7/ADR cells to conventional chemotherapy agents when co-administered (14). Based on these findings and in an attempt to determine the possibility of using GA-13315 as adjuvant to conventional chemotherapy, 
particularly Top1 agents, the present study aimed to investigate whether long-term exposure to a subtoxic dose of GA-13315 would confer resistance to sensitive tumor cell lines, or instead, sensitize the cell line to conventional chemotherapy drugs. Thus, a stepwise GA-13315 induction protocol was applied to human MCF-7 and colon cancer HCT116 cell lines. The chemosensitivity of these cell lines was assessed before and after exposure to GA-13315, and the molecular mechanisms underlying the changes were investigated.

\section{Materials and methods}

Materials. GA-13315 was synthesized by Professor Hong-Bin Zhang and Professor Jing-Bo Chen from the School of Chemical Science and Technology, Yunnan University (Kunming, China). Irinotecan, cisplatin and phenylmethylsulfonyl fluoride (PMSF) were purchased from Sigma-Aldrich; Merck KGaA. TRIzol ${ }^{\circledR}$ reagent and the M-MLV First Strand kit were purchased from Invitrogen; Thermo Fisher Scientific, Inc. RPMI-1640 medium, McCoy's 5A medium, fetal bovine serum (FBS), penicillin and streptomycin were purchased from Gibco; Thermo Fisher Scientific, Inc. The Cell Counting Kit-8 (CCK-8) was purchased from Shanghai life lab Bio Technology Co., Ltd. (http://www.life-ilab.com). Low melting-point agarose and DAPI were purchased from Thermo Fisher Scientific, Inc. The TopoGEN Topoisomerase I Drug Screening kit was purchased from TopoGEN. All other chemicals were of analytical grade and were purchased from commercial sources.

Cell culture. MCF-7 and HCT116 cell lines were purchased from Conservation Genetics CAS Kunming Cell Bank. MCF-7 cells were cultured in RPMI-1640 medium, while HCT116 cells were maintained in McCoy's 5A medium. All cells were supplemented with $10 \% \mathrm{FBS}, 100 \mathrm{IU} / \mathrm{ml}$ penicillin and $100 \mathrm{IU} / \mathrm{ml}$ streptomycin, at $37^{\circ} \mathrm{C}$ in a humidified atmosphere of $5 \% \mathrm{CO}_{2}$.

Evaluation of cell viability. Cells were seeded into 96-well plates at a density of $8 \times 10^{3}$ cells/well in a total volume of $180 \mu \mathrm{l}$ and left to attach overnight at $37^{\circ} \mathrm{C}$. Cells were exposed to drugs $(20 \mu \mathrm{l})$ at different concentrations for $48 \mathrm{~h}$ at $37^{\circ} \mathrm{C}$ and cell viability was subsequently analyzed via the CCK-8 assay at 450 and $630 \mathrm{~nm}$ using SpectraMax Plus384 Molecular Devices (Molecular Devices, LLC), according to the manufacturer's instructions. At least three independent experiments were performed with duplicate determinations. The half maximal inhibitory concentration $\left(\mathrm{IC}_{50}\right)$ values were calculated by non-linear regression, using a sigmoidal dose-response equation (variable slope).

Chronic exposure of cell lines to GA-13315. A reported drug exposure regimen was referred to and followed, with modifications (15). HCT116 cells were exposed to $1 \mu \mathrm{M}$ GA-13315 for 84 days, which yielded $\geq 90 \%$ cell viability. The medium was replaced every 2-3 days with GA-13315 of the same concentration. Sensitivity to chemotherapeutic drugs (GA-13315, irinotecan and cisplatin) was monitored every 4 weeks, with an interval of 2 days during which cells were cultured in the absence of GA-13315 before being plated for sensitivity monitoring. In addition, confluent monolayer cells in $10-\mathrm{cm}$ diameter dishes were either washed twice with PBS and stored at $-80^{\circ} \mathrm{C}$ for protein expression analysis or lysed with TRIzol ${ }^{\circledR}$ reagent and stored at $-80^{\circ} \mathrm{C}$ for mRNA expression analysis. MCF-7 cells were treated with the same procedure as HCT116 cells for 4 weeks and then separated into 2 derivative lines. The first line continued with the same regimen up to 12 weeks, while the second line was exposed to $2 \mu \mathrm{M}$ GA-13315 for 4 weeks and subsequently exposed to $4 \mu \mathrm{M}$ GA-13315 for another 4 weeks. In total, $\geq 90 \%$ of MCF-7 cells were viable at all the aforementioned concentrations of GA-13315.

Western blotting. After chronic exposure to GA-13315 at 4, 8 and 12 weeks, cells were frozen at $-80^{\circ} \mathrm{C}$, respectively. Following successful exposure, cells were thawed and lysed on ice using RIPA lysis buffer (P0013C; Beyotime Institute of Biotechnology) supplemented with $1 \mathrm{mM}$ PMSF, $1 \mu \mathrm{g} / \mathrm{ml}$ aprotinin (Sigma-Aldrich, Merck KGaA), and $0.5 \mu \mathrm{g} / \mathrm{ml}$ leupeptin (Sigma-Aldrich, Merck KGaA). Total protein concentrations were measured using the Micro BCA ${ }^{\mathrm{TM}}$ Protein Assay kit (20151201; Nanjing Jiancheng Bioengineering Institute), and bovine serum albumin was used as standard (16). The gel kit was purchased from Life iLab China (www.life-ilab. com), which can detect protein from 10-250 kDa. Equal amounts of cell lysate ( $20 \mu \mathrm{g}$ of protein) were separated via SDS-PAGE, transferred onto polyvinylidene difluoride membranes and blocked with 5\% skimmed milk in TBST buffer $(10 \mathrm{mM}$ Tris- $\mathrm{HCl}, 150 \mathrm{mM} \mathrm{NaCl}$ and $0.1 \%$ Tween-20; $\mathrm{pH}$ 8.0) for $1 \mathrm{~h}$ at room temperature. The membranes were incubated with primary antibodies against Top1 (1:10,000; cat. no. ab109374; Abcam), tyrosyl DNA phosphodiesterase 1 (Tdp1; 1:1,000; cat. no. 2360; Cell Signaling Technology, Inc.), Chk1 (cat. no. 59710; Cell Signaling Technology, Inc.), Bax (1:10,000; cat. no. ab32503; Abcam), Bcl-2 (1:1,000; cat. no. ab32124; Abcam) and $\beta$-actin (1:5,000; cat. no. ab8227; Abcam) overnight at $4^{\circ} \mathrm{C}$. Membranes were washed three times with distilled water and subsequently incubated with horseradish peroxidase-conjugated goat anti-rabbit IgG secondary antibody (1:3,000; L3001; Signalway Antibody LLC) for $2 \mathrm{~h}$ at room temperature. Protein bands were visualized using the enhanced Phototope TM-HRP Detection kit (Cell Signaling Technology, Inc.) and captured using a FluorChem E Imaging system (ProteinSimple). Relative protein expression was measured by densitometry using ImageJ $1.49 \mathrm{v}$ software (National Institutes of Health).

Reverse transcription-quantitative $(R T-q) P C R$. mRNA expression levels of Top1, Tdp1, Chk1, Bax and Bcl-2 were analyzed via RT-qPCR analysis. Confluent monolayer cells in 10-cm diameter dishes were extracted using TRIzol ${ }^{\circledR}$ reagent. First strand cDNA was synthesized from $1 \mu \mathrm{g}$ total RNA using the M-MLV First Strand kit and the genes of interest were amplified using the SYBR ${ }^{\circledR}$ Premix Select Master Mix kit (Thermo Fisher Scientific, Inc.) and an ABI PRISM ${ }^{\circledR} 7500$ Real-Time PCR system (Applied Biosystems; Thermo Fisher Scientific, Inc.). The primer sequences used for qPCR are listed in Table I. The following thermocycling conditions were used for qPCR: $50^{\circ} \mathrm{C}$ for $2 \mathrm{~min}, 95^{\circ} \mathrm{C}$ for $2 \mathrm{~min}$, followed by 40 cycles at $95^{\circ} \mathrm{C}$ for $15 \mathrm{sec}, 56^{\circ} \mathrm{C}$ for $15 \mathrm{sec}$ and $72^{\circ} \mathrm{C}$ for 


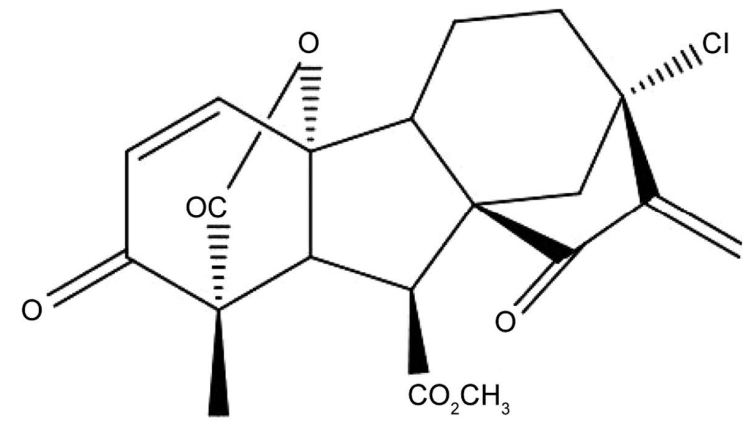

Figure 1. Chemical structure of 13-chlorine-3,15-dioxy-gibberellic acid methyl ester.

$1 \mathrm{~min}$. Specificity of each reaction was verified by the melt curve stage, at $95^{\circ} \mathrm{C}$ for $15 \mathrm{sec}, 55^{\circ} \mathrm{C}$ for $1 \mathrm{~min}$ and $95^{\circ} \mathrm{C}$ for $30 \mathrm{sec}$. Relative mRNA levels of the genes of interest in each group were calculated using the $2^{-\Delta \Delta \mathrm{Cq}}$ method $\left[\Delta \mathrm{Cq}=\mathrm{Cq}_{\text {target }}\right.$ gene $\left.-\mathrm{Cq}_{\beta \text {-actin }} ;-\Delta \Delta \mathrm{Cq}=-\left(\Delta \mathrm{Cq}_{\text {sample }}-\Delta \mathrm{Cq}_{\mathrm{control}}\right)\right]$, as the mean value of three independent samples determined in triplicates, and normalized to the internal reference gene $\beta$-actin (17).

DNA agarose gel electrophoresis. To assess DNA fragmentation, MCF-7 and HCT-116 cells were treated with a compound (irinotecan, cisplatin or GA-13315) at the concentration of $\mathrm{IC}_{50}$ for $48 \mathrm{~h}$ and subsequently subjected to agarose gel electrophoresis, following the reported protocol (18). Briefly, cells were harvested and washed twice with ice-cold PBS. A total of $1 \times 10^{5}$ cells were suspended in $130 \mu 1$ of $0.7 \%$ low melting-point agarose and subsequently layered on a fully frosted slide. The slides were pre-coated with $80 \mu 1$ of $1 \%$ normal melting-point agarose, which was set aside to solidify. The slides were incubated in freshly prepared alkaline lysis buffer [2.5 mM NaCl (20190104; Guangdong Guanghua Sci-Tech Co Ltd China), $100 \mathrm{mM} \mathrm{Na}$-EDTA (Invitrogen; Thermo Fisher Scientific, Inc.), 10 mM Tris-HCl (20180919; Beijing Solarbio Science \& Technology Co., Ltd.), 1\% sodium lauroylsarcosinate (P1293625; Adamas-Beta, Ltd., 1\% Triton X-100 (Beyotime Institute of Biotechnology) and $10 \%$ DMSO (201508; Amresco, LLC; pH 10] for $1 \mathrm{~h}$ at $4^{\circ} \mathrm{C}$ in the dark. Subsequently, the slides were immersed in electrophoresis buffer [ $1 \mathrm{mM} \mathrm{Na}{ }_{2}$-EDTA (Invitrogen; Thero Fisher Scientific, Inc.) and $300 \mathrm{mM} \mathrm{NaOH}$ (pH 13) (1304282; Xilong Scientific Co., Ltd. (http://www.xlhg.com)] for $30 \mathrm{~min}$ at room temperature and subjected to electrophoresis at $25 \mathrm{~V}$ for $30 \mathrm{~min}$. The slides were rinsed with $0.4 \mathrm{M}$ Tris buffer ( $\mathrm{pH} 7.5$ ), stained with DAPI $(1 \mu \mathrm{g} / \mathrm{ml})$ at room temperature for $30 \mathrm{sec}$ and observed under a fluorescence microscope (DMI300B; Leica Microsystems $\mathrm{GmbH}$, magnification, x40).

Topl assay. Inhibition of Top1 was assessed using the TopoGEN Topoisomerase I Drug Screening kit (cat. no. 18FB14, https://www.topogen.com), according to the manufacturer's protocol. Briefly, $0.2 \mu \mathrm{g}$ of the supercoiled plasmid DNA (pHOT1) substrate was incubated with 4 units of Top1 enzymes, in the presence or absence of GA-13315, in Top1 reaction buffer for $30 \mathrm{~min}$ at $37^{\circ} \mathrm{C}$. Reactions were terminated by adding $10 \%$ SDS (322R032; Beijing Solarbio Science \& Technology Co., Ltd.) followed by treatment with proteinase K (D00091408; Calbiochem, Inc.). Samples were mixed with loading buffer, loaded onto a $1 \%$ agarose gel and electrophoresis was performed at $25 \mathrm{~V}$ for $4 \mathrm{~h}$ in TAE buffer (pH 8.0) (Sigma-Aldrich; Merck KGaA). Gels were stained with $0.5 \mu \mathrm{g} / \mathrm{ml}$ ethidium bromide at room temperature for $30 \mathrm{~min}$ (cat. no. 0492; Invitrogen; Thermo Fisher Scientific, Inc.) and rinsed with distilled water. DNA was visualized under a UV lamp and captured using a FluorChem E Imaging System (ProteinSimple). For determination of Top1-mediated DNA cleavage, another set of samples of similar reactions were loaded onto a $1 \%$ agarose gel containing $0.5 \mu \mathrm{g} / \mathrm{ml}$ ethidium bromide, and electrophoresed in order to resolve nicked DNA from supercoiled or relaxed DNA (19). Camptothecin $(0.1 \mathrm{mM})$ was used as the positive control.

Statistical analysis. Statistical analysis was performed using GraphPad Prism software (version 5.0; GraphPad Software, Inc.). Data are presented as the mean \pm standard deviation. One-way ANOVA followed by Tukey's post-hoc test was used to compare differences between multiple groups. $\mathrm{P}<0.05$ was considered to indicate a statistically significant difference.

\section{Results}

Sensitivity changes following exposure to GA-13315. The sensitivity of MCF-7 and HCT116 cells to GA-13315, irinotecan and cisplatin, before and after chronic GA-13315 exposure was assessed (Fig. S1 and Table II). The results demonstrated that exposure to $1 \mu \mathrm{M}$ GA-13315 for 4 weeks increased the susceptibility of MCF-7 cells to GA-13315; however, this effect waned overtime $(\mathrm{P}<0.01$ at 4 weeks vs. $\mathrm{P}>0.05$ at 8 and 12 weeks, respectively). Notably, exposure to higher concentrations of GA-13315 ( 2 and $4 \mu \mathrm{M})$ did not alter the susceptibility of MCF-7 cells to this compound. However, the sensitivity of MCF-7 cells to irinotecan enhanced in a time-dependent manner following chronic GA-13315 exposure $(1 \mu \mathrm{M})$, as the $\mathrm{IC}_{50}$ of irinotecan decreased significantly from 4 weeks $(\mathrm{P}<0.001$ vs. 0 weeks) and decreased even more at 8 and 12 weeks, respectively ( $\mathrm{P}<0.001$ vs. 4 weeks). The increase in the concentration of GA-13315 did not incur stronger cytotoxicity of irinotecan. The sensitivity of MCF-7 cells to cisplatin remained unchanged by GA-13315, regardless of the exposure time and concentration.

Following chronic exposure to GA-13315, sensitivity of HCT116 cells remained unchanged; however, compared with MCF-7 cells, HCT116 cells acquired resistance following long-term exposure to irinotecan ( 8 weeks vs. 0 weeks, $\mathrm{P}<0.01 ; 12$ weeks vs. 0 weeks, $\mathrm{P}<0.05)$. GA-13315 exposure also conferred HCT116 resistance to cisplatin $(\mathrm{P}<0.05$, 8 and 12 weeks vs. 0 weeks) and the degree of resistance was associated with exposure time $(\mathrm{P}<0.05,8$ and 12 weeks vs. 0 and 12 weeks vs. 8 weeks).

Alterations in expression of proteins involved in chemosensitivity following exposure to GA-13315. As presented in Fig. 2, western blot analysis demonstrated that chronic GA-13315 exposure caused a time-dependent decrease of Top1 protein expression in MCF-7 cells, whereas the same regimen increased Top1 protein expression in HCT116 cells 
Table I. Sequences of oligos used for quantitative PCR.

\begin{tabular}{lll}
\hline Gene & \multicolumn{1}{c}{ Forward primer } & \multicolumn{1}{c}{ Reverse primer } \\
\hline Top1 & 5'-TGACAGCCCCGGATGAGA-3' & 5'-TGCAACAGCTCGATTGGC-3' \\
TdpI & 5'-GCAGCAGCATCATTTTCGTGT-3' & 5'-GCTTGTGCATGGTGATAAGCG-3' \\
Chk1 & 5'-GGCTCTGGGGAATCCTGGTGAATATA & 5'-GGCTCTGGGGAATCCTGGTGAATATAGT \\
& GTGCTGC-3' & GCTGC-3' \\
Bax & 5'-AGGATGCGTCCACCAAGAAG-3' & 5'-TGAAGTTGCCGTCAGAAAACA-3' \\
Bcl-2 & 5'-ATGTGTGTGGAGAGCGTCAACC-3' & 5'-TGAGCAGAGTCTTCAGAGACAGCC-3' \\
$\beta$-actin & 5'-CACCTTCTACAATGAGCTGCGTGTG-3' & 5'-ATAGCACAGCCTGGATAGCAACGTAC-3'
\end{tabular}

Top1, topoisomerase I; Tdp1, tyrosyl DNA phosphodiesterase 1; Chk1, checkpoint kinase 1; Bcl-2, B-cell lymphoma 2.

Table II. Change in sensitivity of MCF-7 and HCT116 cells following chronic GA-13315 exposure.

A, MCF-7 cells

\begin{tabular}{llcr}
\hline & \multicolumn{3}{c}{$\mathrm{IC}_{50} \pm$ standard deviation, $\mu \mathrm{M}$ (sensitizing fold) } \\
\cline { 2 - 4 } GA-13315 concentration & $\mathrm{GA}-13315$ & Irinotecan & Cisplatin \\
\hline $1 \mu \mathrm{M}$ & & & $5.10 \pm 0.54$ \\
Week 0 & $36.70 \pm 2.39$ & $35.58 \pm 0.75$ & $5.45 \pm 0.91(0.9)$ \\
Week 4 & $30.12 \pm 1.72(1.2)^{\mathrm{a}}$ & $16.69 \pm 2.20(1.6)^{\mathrm{b}}$ & $4.41 \pm 0.30(1.4)$ \\
Week 8 & $40.27 \pm 0.43(0.9)^{\mathrm{c}}$ & $15.19 \pm 0.53(2.3)^{\mathrm{b}, \mathrm{c}}$ & $5.29 \pm 0.27(1.0)$ \\
Week 12 & $38.73 \pm 1.87(0.9)^{\mathrm{c}}$ & & \\
$2 \mu \mathrm{M}$ & & $15.13 \pm 1.25(2.4)^{\mathrm{b}}$ & \\
Week 12 & $35.78 \pm 1.40(1.0)$ & & $4.88 \pm 0.38(1.0)$ \\
$4 \mu \mathrm{M}$ & & $14.11 \pm 0.78(2.5)^{\mathrm{b}}$ & $5.61 \pm 0.40(0.9)$ \\
Week 12 & $37.25 \pm 4.35(1.0)$ & & \\
\hline
\end{tabular}

B, HCT116 cells

\begin{tabular}{|c|c|c|c|}
\hline \multirow[b]{2}{*}{ GA- 13315 concentration } & \multicolumn{3}{|c|}{$\mathrm{IC}_{50} \pm$ standard deviation, $\mu \mathrm{M}$ (sensitizing fold) } \\
\hline & GA-13315 & Irinotecan & Cisplatin \\
\hline \multicolumn{4}{|l|}{$1 \mu \mathrm{M}$} \\
\hline Week 0 & $7.37 \pm 0.83$ & $1.52 \pm 0.02$ & $6.25 \pm 1.09$ \\
\hline Week 4 & $7.47 \pm 0.41(1.0)$ & $2.29 \pm 0.24(0.7)$ & $6.11 \pm 0.40(1.0)$ \\
\hline Week 8 & $6.57 \pm 0.34(1.1)$ & $5.74 \pm 1.66(0.3)^{\mathrm{a}, \mathrm{c}}$ & $9.94 \pm 1.82(0.6)^{\mathrm{c}, \mathrm{d}}$ \\
\hline Week 12 & $7.95 \pm 0.10(0.9)$ & $4.54 \pm 0.68(0.4)^{\mathrm{d}}$ & $12.58 \pm 0.73(0.5)^{\mathrm{b}, \mathrm{c}, \mathrm{e}}$ \\
\hline
\end{tabular}

and downregulated Tdp1 protein expression. However, Tdp1 protein expression was not observed in MCF-7 cells. Chk1 expression did not change in MCF-7 cells following exposure to GA-13315; however, Chk1 expression levels increased in a time-dependent manner in HCT116 cells. Bax protein expression increased in both MCF-7 and HCT116 cells; however, different peak times were exhibited (12 weeks for MCF-7 cells vs. 8 weeks for HCT116 cells). Bcl-2 protein expression also increased in a time-dependent manner in MCF-7 cells; however, Bcl-2 expression remained unchanged in HCT-116 cells following chronic GA-13315 exposure.

mRNA expression of the genes involved in chemosensitivity following exposure to GA-13315. As presented in Fig. 3, Top1 
A
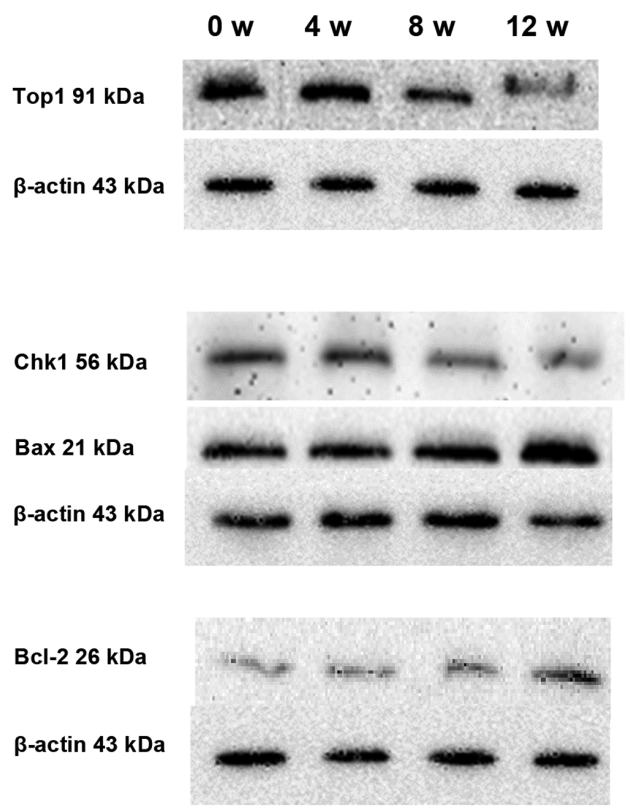

HCT116 cells

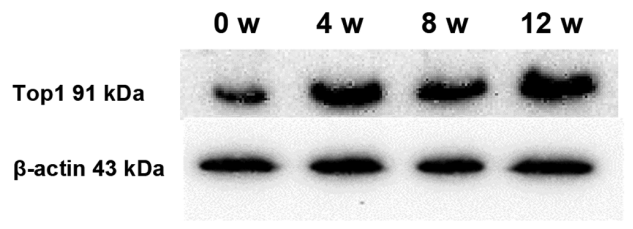

Tdp1 $70 \mathrm{kDa}$

Bcl-2 26 kDa

$\beta$-actin $43 \mathrm{kDa}$

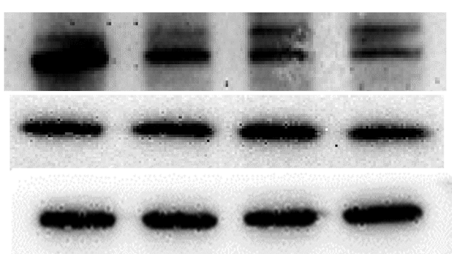

Chk1 $56 \mathrm{kDa}$

Bax $21 \mathrm{kDa}$

$\beta$-actin 43 kDa

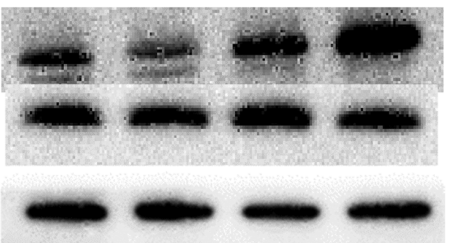

\section{B}
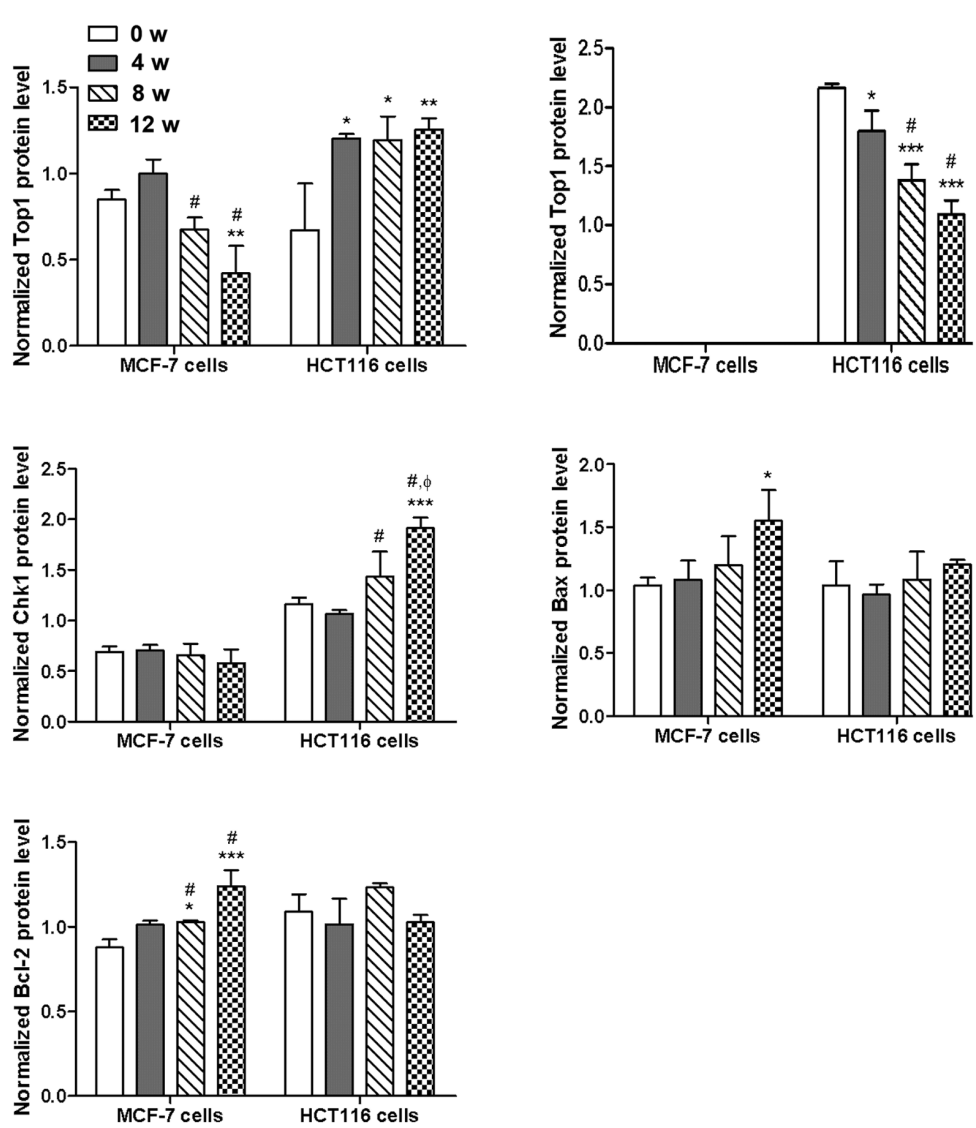

Figure 2. Effect of 13-chlorine-3,15-dioxy-gibberellic acid methyl ester on the expression of proteins involved in the chemosensitivity of tumor cell lines. (A) Protein expression levels were normalized to $\beta$-actin and quantified using ImageJ v1.49 software, and (B) data are presented as the mean \pm standard deviation of three independent experiments. ${ }^{*} \mathrm{P}<0.05,{ }^{* *} \mathrm{P}<0.01$ and ${ }^{* * * *} \mathrm{P}<0.001$ vs. 0 weeks (control); ${ }^{*} \mathrm{P}<0.05$ vs. 4 weeks; ${ }^{*} \mathrm{P}<0.05$ vs. 8 weeks. Top1, topoisomerase I; Tdp1, tyrosyl DNA phosphodiesterase 1; Chk1, checkpoint kinase 1; Bcl-2, B-cell lymphoma-2.

and Chk1 mRNA expression levels in HCT116 cells were consistent with the protein expression patterns; however, Top1 and Chk1 mRNA expression levels both increased in a time-dependent manner in MCF-7 cells following chronic
GA-13315 exposure, which was disassociated with the protein expression. As for Bax and Bcl-2, the changes in mRNA expression levels were in accordance with that of its protein expression patterns in HCT116 cells; however, Bax mRNA 
A

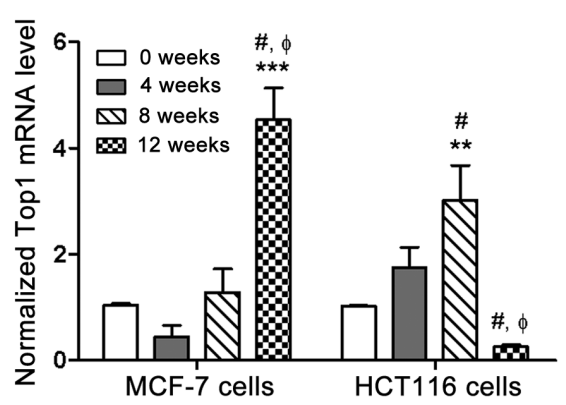

C

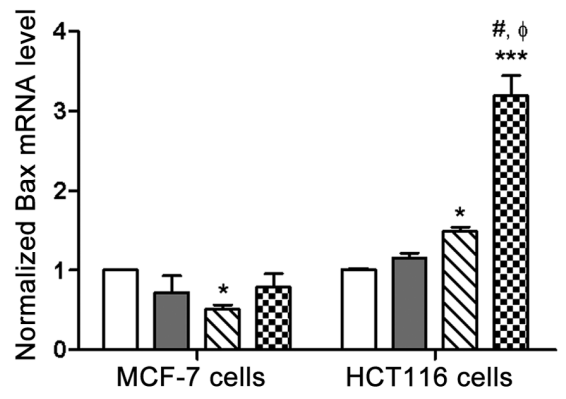

B

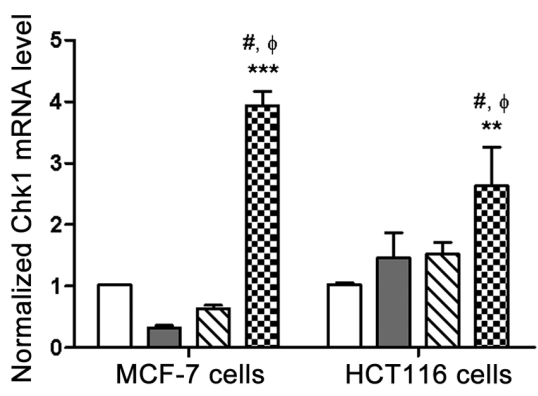

D

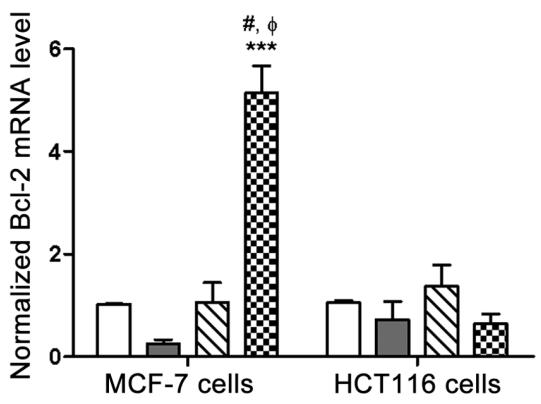

Figure 3. Effect of 13-chlorine-3,15-dioxy-gibberellic acid methyl ester on the mRNA expression levels of genes involved in the chemosensitivity of tumor cell lines. Reverse transcription-quantitative PCR analysis was performed to determine the mRNA expression levels of (A) Top1, (B) Chk1, (C) Bax and (D) Bcl-2 in MCF-7 and HCT116 cells. Data are presented as the mean \pm standard deviation of three independent experiments. ${ }^{*}<<0.05,{ }^{* *} \mathrm{P}<0.01$ and ${ }^{* * *} \mathrm{P}<0.001$ vs. 0 week (control); ${ }^{~} \mathrm{P}<0.05$ vs. 4 weeks; ${ }^{\phi} \mathrm{P}<0.05$ vs. 8 weeks. Top1, topoisomerase I; Chk1, checkpoint kinase 1; Bcl-2, B-cell lymphoma-2.

expression decreased, while Bax protein expression increased, and $\mathrm{Bcl}-2$ mRNA expression increased, while $\mathrm{Bcl}-2$ protein expression remained unchanged in MCF-7 cells. The chronic exposure of GA-13315 on MCF-7 and HCT116 cells was up to 12 weeks, and 4 time points $(0,4,8$ and 12 weeks) were monitored to depict the changes of relevant mRNA and protein levels. Top1 mRNA expression significantly decreased at 12 weeks compared with 0 week. Bax mRNA expression gradually increased and only significantly changed at 12 weeks; however, this was not reflected on protein expression level. The chronic exposure of GA-13315 on MCF-7 and HCT116 cells did not significantly affect the apoptosis pathway, but affected the translation process, as the mRNA and protein expression levels were inconsistent.

Effect of GA-13315 on DNA integrity of tumor cells. To determine the effect of GA-13315 on DNA integrity, MCF-7 and HCT116 cells were treated with GA-13315 for $48 \mathrm{~h}$ and subsequently subjected to single-cell agarose gel electrophoresis. As presented in Fig. 4, GA-13315 caused DNA fragmentation, as did the Top1 poison irinotecan and the DNA alkylating agent cisplatin, in both MCF-7 and HCT116 cells, which was manifested by visible comet tail-like features following electrophoresis.

Effect of GA-13315 on Topl activity. The effects of GA-13315 on the catalytic activity of Top1 and Top1-mediated DNA cleavage were determined via the Top1 relaxation assay. As presented in Fig. 5, GA-13315 inhibited the catalytic activity of Top1 in a manner similar to the reference drug irinotecan, as demonstrated by the decreased amount of relaxed DNA and increased amount of supercoiled DNA. Although irinotecan inhibited DNA cleavage activity of Top1, which was indicated by the formation of nicked DNA in the presence of $50 \mu \mathrm{M}$ irinotecan, GA-13315 did not affect DNA cleavage mediated by Top1 at the highest concentration $(100 \mu \mathrm{M})$. This suggests that the mechanism of inhibition of GA-13315 on Top1 differs from that of irinotecan.

\section{Discussion}

In our previous study, GA-13315, a cytotoxic compound that exhibits selectivity to the ABCB1-overexpressing multidrug-resistant MCF-7/ADR cells when administered alone (14), was evidenced to reverse the resistance of MCF-7/ADR cells when administered at subtoxic doses in combination with several chemotherapeutic agents (14). Following this finding, the present study aimed to investigate the potential of GA-13315 being used as an auxiliary agent to conventional chemotherapy, and was designed to evaluate the influence of long-term treatment with GA-13315 (at low dose) on sensitive tumor cell lines. The results of the present study demonstrated that chronic exposure to low-dose GA-13315 up to 12 weeks did not render either MCF-7 or HCT116 cells resistant to GA-13315. Notably, MCF-7 cells became more susceptible to GA-13315 following 4 weeks of exposure; however, this sensitizing effect receded in a time-dependent manner. Taken together, these results suggest that GA-13315 may be used in antitumor therapy, as it is not prone to induce resistance in tumor cells. However, considering that the exposure time in the present study was only 12 weeks, the potential of GA-13315 conferring resistance to tumor cells if the exposure time extends beyond 12 weeks cannot be excluded.

The chronic exposure of GA-13315 on MCF-7 and HCT116 cells had different effects, as their sensitivities to irinotecan and cisplatin were inconsistent. The results of the present study demonstrated that GA-13315 did not alter the sensitivity of either MCF-7 or HCT116 cells to cisplatin, but increased 


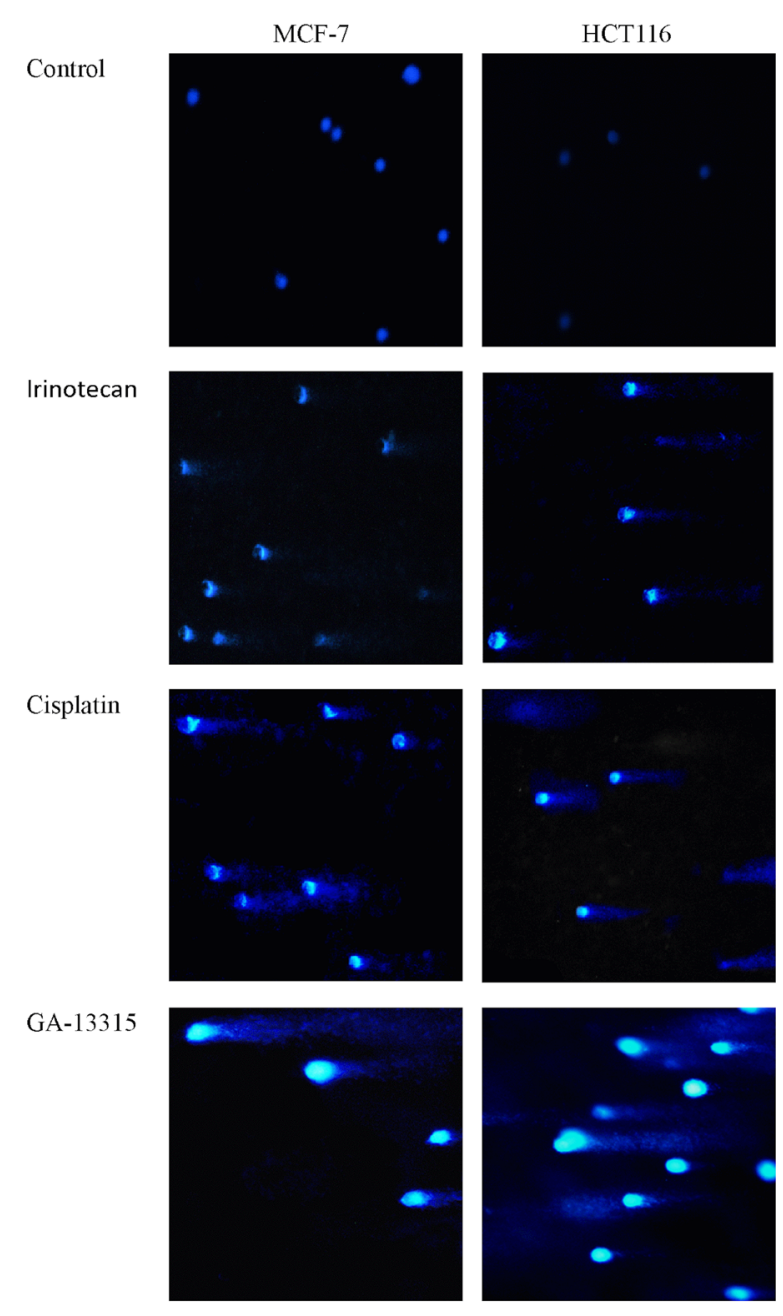

Figure 4. Effect of GA-13315 on DNA fragmentation. Cells were treated with irinotecan, cisplatin and GA- 13315 for $48 \mathrm{~h}$ at the $\mathrm{IC}_{50}$ concentration, underwent chronic GA-13315 exposure and were subjected to single-cell electrophoresis. DNA fragmentation was indicated by the comet tail visualized by DAPI staining (magnification, x40). GA-13315, 13-chlorine-3,15-dioxy-gibberellic acid methyl ester.

the sensitivity of MCF-7 cells to the Top1 poison irinotecan, while rendering HCT-116 cells more resistant to cisplatin. Collectively, these results suggest that the alteration of the chemosensitivity of tumor cells by GA-13315 may be associated with Top1 activity-mediated mechanisms. Top1 removes DNA supercoils during transcription and replication by cutting a single strand of DNA to allow relaxation of torsional stresses and subsequent reannealing $(20,21)$. An intermediate, known as the cleavage complex, consisting of Top1 covalently attached to the cleaved DNA, is formed transiently in this process (22-24). This cleavage complex is stabilized by irinotecan (in the form of active metabolite SN38) (25), which collides with advancing replication forks, resulting in single strand breaks in DNA, eventually leading to cell cycle arrest and cell death $(26,27)$. Top1 poison-mediated DNA damage can be repaired by hydrolysis of the phosphodiester bond between Top1 and the 3'-phosphate of DNA to disassemble the stalled cleavage complex, and this process is catalyzed by Tdp1 $(28,29)$. Top1 poison also elicits activation of the Chk1 pathway, which is efficiently coupled with DNA repair to prevent further replication-dependent DNA damage (30-32).

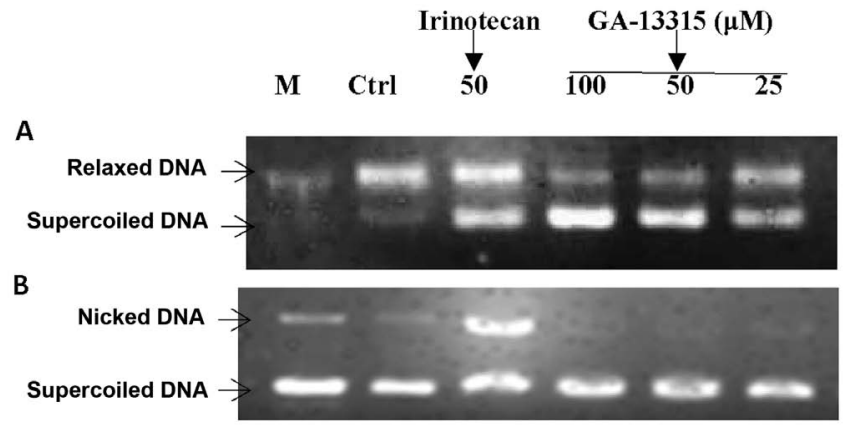

Figure 5. Effect of GA-13315 on the catalytic activity of (A) Top1 and (B) Top1-mediated DNA cleavage. GA-13315 inhibited the catalytic activity of Top1 in a dose-dependent manner, which was demonstrated by the increased amount of supercoiled DNA as the concentration of GA-13315 increased. GA-13315 did not affect Top1-mediated DNA cleavage, evidenced by the lack of nicked DNA in the presence of GA-13315. CPT-11 $(50 \mu \mathrm{M})$ was used as the reference drug. The control test was performed using $0.1 \%$ DMSO instead of GA-13315. GA-13315, 13-chlorine-3,15-dioxy-gibberellic acid methyl ester; M, marker; Ctrl, control.

Elevation of Top1 mRNA, protein and catalytic activity in human tumors have been reported, with particularly high Top1 expression in colorectal cancer, while Tdp1 exhibits significantly higher expression levels in non-small cell lung cancer and breast cancer tissues compared with normal tissues $(26,33,34)$. Upon Top1 poison exposure, Top1 expression decreases in tumor cells, which induces drug resistance to Top1 poisons in human glioblastoma cells (26). Suppression of Tdp1 results in cellular defects in the repair of Top1-mediated DNA breaks $(28,29)$. Tdp1-knockout mice are viable but hypersensitive to irinotecan (35). Irinotecan also induces Chk1 degradation (36), while downregulation of Chk1 potentiates the cytotoxicity of irinotecan in tumor cells, such as A549 lung carcinoma cells, HeLa cells and MCF-7 cells (30-32,36). The present study assessed the expression levels of Top1 in both MCF-7 and HCT116 cells. The results demonstrated that the sensitivity of GA-13315-exposed cells to irinotecan was associated with Top1. The protein expression of Top1 was upregulated in MCF-7 cells as the sensitivity of MCF-7 cells to irinotecan increased. Conversely, Top1 protein expression was downregulated in HCT116 cells. Elevated Top1 expression coincided with decreased Tdp1 expression in HCT116 cells; however, Tdp1 expression was not detected in MCF-7 cells, both before or after chronic GA-13315 exposure. Chk1 expression increased in HCT116 cells following GA-13315 exposure, which coincided with the enhanced resistance of HCT116 cells to irinotecan; however, these resistant effects were not observed in MCF-7 cells. Taken together, these results suggest that the sensitivity of tumor cells to irinotecan may be in inverse ratio to Top1 expression in cell lines that express low levels of Tdp1 or Chk1. Although GA-13315 was not able to sensitize HCT116 cells to irinotecan, the cytotoxicity of GA-13315 itself to HCT116 cells and the maintenance of sensitivity of HCT116 cells to GA-13315 upon chronic exposure may be attributed to the downregulation of Tdp1 caused by GA-13315. In addition, as GA-13315 exposure resulted in increased Top1 and Chk1 expression in HCT116 cells, GA-13315 may function through a mechanism different from that of irinotecan, which has been reported to decrease Top1 and Chk1 expression levels in tumor cells $(30,35)$. 
In order to determine the underlying molecular mechanisms of GA-13315, the present study investigated the effect of GA-13315 on DNA integrity by performing single-cell agarose gel electrophoresis. Short-term (48-h) GA-13315 treatment at a relatively high concentration $\left(\mathrm{IC}_{50}\right)$ resulted in DNA fragmentation, as did treatment with the reference drugs irinotecan and cisplatin; however, the results failed to determine whether DNA damage was the consequence of the direct interaction of GA-13315 with DNA or if it was mediated by Top1. The in vitro Top1 assay demonstrated that GA-13315 was not Top1 poison, but actually inhibited the catalytic activity of Top1, which supported the initial hypothesis that GA-13315 has different mechanisms of action from irinotecan.

Given that the apoptotic pathway plays a substantial role in the alterations of chemosensitivity of tumor cells, the present study assessed the changes in expression levels of the proapoptotic factor, Bax, and the antiapoptotic regulator, Bcl-2 (37-39). No significant alteration in the ratio of $\mathrm{Bax} / \mathrm{Bcl}-2$ was observed, which indicates the activity of the apoptotic pathway (40). This implies that the mechanisms of action of chronic GA-13315 exposure may be different from that of the apoptotic pathways. Notably, in the MCF-7 cell line, which was sensitized to irinotecan by GA-13315, the changes in mRNA expression levels were uncoupled with that of the protein expression levels for Top1, Chk1 and Bax. This imbalance between gene and protein expression levels may be caused by the potential effects of GA-13315 on the mRNA (half-life) stability (41-43). This phenomenon was not observed in HCT116 cells, thus the sensitizing effect of GA-13315 was probably associated with the disruption of the protein translation process; however, this hypothesis requires further investigation.

In the present study, GA-13315 failed to induce drug resistance in either MCF-7 or HCT116 cells when administered at a subtoxic dose for 12 weeks. Chronic GA-13315 exposure was able to potentiate the cytotoxicity of the Top1 poison irinotecan to MCF-7 cells, which barely express Tdp1; however, this effect was not observed in HCT116 cells. The sensitivity of cells to irinotecan following GA-13315 exposure was in direct ratio to Top1 expression, while in inverse ratio to the expression levels of Tdp1 and Chk1. Mechanistic analysis demonstrated that GA-13315 caused DNA damage, but not via a Top1-dependent manner, as GA-13315 was not a Top1 poison despite inhibiting the catalytic activity of Top1. As the responses of different cell lines upon chronic GA-13315 exposure to chemotherapy drugs were inconsistent, GA-13315 may not be used universally as an adjuvant to chemotherapy; however, the mechanism of its influence on the sensitivity and resistance of tumor cell lines merits further investigation in light of discovering new pathways and strategies to overcome drug resistance in cancer.

\section{Acknowledgements}

Not applicable.

\section{Funding}

The present study was supported by the Natural Science Foundation of Yunnan Province, China (grant no. 2017FE468), the National Natural Science Foundation of China (grant nos. 81460559 and 81160405) and the Ding Jian Academician Workstation and Collaborative Innovation Center for Natural Products and Biological Drugs of Yunnan of China (grant no. YSGZZ201310).

\section{Availability of data and materials}

The datasets used and/or analyzed during the present study are available from the corresponding author upon reasonable request.

\section{Authors' contributions}

$\mathrm{CQ}$ and $\mathrm{JM}$ designed the present study. XC, GW and YL performed the experiments. JM and CQ analyzed the data. JM and XC drafted the initial manuscript. All authors have read and approved the final manuscript.

\section{Ethics approval and consent to participate}

Not applicable.

\section{Patient consent for publication}

Not applicable.

\section{Competing interests}

The authors declare that they have no competing interests.

\section{References}

1. Schoeffler AJ and Berger JM: DNA topoisomerases: Harnessing and constraining energy to govern chromosome topology. Q Rev Biophys 41: 41-101, 2008.

2. Li TK and Liu LF: Tumor cell death induced by topoisomerase-targeting drugs. Annu Rev Pharmacol Toxicol 41: 53-77, 2001.

3. Wu CP, Calcagno AM and Ambudkar SV: Reversal of ABC drug transporter-mediated multidrug resistance in cancer cells: Evaluation of current strategies. Curr Mol Pharmacol 1: 93-105, 2008.

4. Velasquez WS, Lew D, Grogan TM, Spiridonidis $\mathrm{CH}$ Balcerzak SP, Dakhil SR, Miller TP, Lanier KS, Chapman RA and Fisher RI; Southwest Oncology Group: Combination of fludarabine and mitoxantrone in untreated stages III and IV low-grade lymphoma: S9501. J Clin Oncol 21: 1996-2003, 2003.

5. Gotwals P, Cameron S, Cipolletta D, Cremasco V, Crystal A, Hewes B, Mueller B, Quaratino S, Sabatos-Peyton C, Petruzzelli L, et al: Prospects for combining targeted and conventional cancer therapy with immunotherapy. Nat Rev Cancer 17: 286-301, 2017.

6. Johnson BE: Concurrent approaches to combined chemotherapy and chest radiotherapy for the treatment of patients with limited stage small cell lung cancer. Lung Cancer 10 (Suppl 1): S281-S287, 1994.

7. Zhu Y, Liu C, Armstrong C, Lou W, Sandher A and Gao AC: Antiandrogens inhibit ABCB1 Efflux and ATPase activity and reverse docetaxel resistance in advanced prostate cancer. Clin Cancer Res 21: 4133-4142, 2015.

8. Palmeira A, Sousa E, Vasconcelos MH and Pinto MM: Three decades of P-gp inhibitors: Skimming through several generations and scaffolds. Curr Med Chem 19: 1946-2025, 2012.

9. Chen Z, Shi T, Zhang L, Zhu P, Deng M, Huang C, Hu T, Jiang L and Li J: Mammalian drug efflux transporters of the ATP binding cassette $(\mathrm{ABC})$ family in multidrug resistance: A review of the past decade. Cancer Lett 370: 153-164, 2016.

10. Yuan H, Li X, Wu J, Li J, Qu X, Xu W and Tang W: Strategies to overcome or circumvent P-glycoprotein mediated multidrug resistance. Curr Med Chem 15: 470-476, 2008. 
11. Bomke $\mathrm{C}$ and Tudzynski B: Diversity, regulation, and evolution of the gibberellin biosynthetic pathway in fungi compared to plants and bacteria. Phytochemistry 70: 1876-1893, 2009.

12. Chen J, Sun Z, Zhang Y, Zeng X, Qing C, Liu J, Li L and Zhang H: Synthesis of gibberellin derivatives with anti-tumor bioactivities. Bioorg Med Chem Lett 19: 5496-5499, 2009.

13. Zhang Y, Zhang $\mathrm{H}$, Chen J, Zhao H, Zeng X, Zhang $\mathrm{H}$ and Qing C: Antitumor and antiangiogenic effects of GA-13315, a gibberellin derivative. Invest New Drugs 30: 8-16, 2012.

14. Mo J, Kang M, Ye JX, Chen JB, Zhang HB and Qing C: Gibberellin derivative GA-13315 sensitizes multidrug-resistant cancer cells by antagonizing ABCB1 while agonizes ABCC1. Cancer Chemother Pharmacol 78: 51-61, 2016.

15. Das SG, Hermanson DL, Bleeker N, Lowman X, Li Y, Kelekar A and Xing C: Ethyl 2-amino-6-(3,5-dimethoxyphenyl)-4(2-ethoxy-2-oxoethyl)-4H-chromene-3-carboxylate (CXL017): A novel scaffold that resensitizes multidrug resistant leukemia cells to chemotherapy. ACS Chem Biol 8: 327-335, 2013.

16. Walker JM: The bicinchoninic acid (BCA) assay for protein quantitation. Methods Mol Biol 32: 5-8, 1994.

17. Livak KJ and Schmittgen TD: Analysis of relative gene expression data using real-time quantitative PCR and the 2(-Delta Delta C(T)) method. Methods 25: 402-408, 2001.

18. Sabisz M, Wesierska-Gadek J and Skladanowski A: Increased cytotoxicity of an unusual DNA topoisomerase II inhibitor compound C-1305 toward HeLa cells with downregulated PARP-1 activity results from re-activation of the p53 pathway and modulation of mitotic checkpoints. Biochem Pharmacol 79 $1387-1397,2010$

19. Patra N, De U, Kang JA, Kim JM, Ahn MY, Lee J, Jung JH, Chung HY, Moon HR and Kim HS: A novel epoxypropoxy flavonoid derivative and topoisomerase II inhibitor, MHY336, induces apoptosis in prostate cancer cells. Eur J Pharmacol 658: 98-107, 2011

20. Champoux JJ: DNA topoisomerases: Structure, function, and mechanism. Annu Rev Biochem 70: 369-413, 2001.

21. Peterson KE, Cinelli MA, Morrell AE, Mehta A, Dexheimer TS, Agama K, Antony S, Pommier Y and Cushman M: Alcohol-, diol-, and carbohydrate-substituted indenoisoquinolines as topoisomerase I inhibitors: Investigating the relationships involving stereochemistry, hydrogen bonding, and biological activity. J Med Chem 54: 4937-4953, 2011.

22. Chen AY and Liu LF: DNA topoisomerases: Essential enzymes and lethal targets. Annu Rev Pharmacol Toxicol 34: 191-218, 1994.

23. Hsiang YH, Lihou MG and Liu LF: Arrest of replication forks by drug-stabilized topoisomerase I-DNA cleavable complexes as a mechanism of cell killing by camptothecin. Cancer Res 49 : 5077-5082, 1989.

24. Liu LF, Desai SD, Li TK, Mao Y, Sun M and Sim SP: Mechanism of action of camptothecin. Ann NY Acad Sci 922: 1-10, 2000.

25. Irinotecan. In: Drugs and Lactation Database (LactMed) National Library of Medicine (US), Bethesda, MD, 2006.

26. Gilbert DC, Chalmers AJ and El-Khamisy SF: Topoisomerase I inhibition in colorectal cancer: Biomarkers and therapeutic targets. Br J Cancer 106: 18-24, 2012.

27. Li F, Jiang T, Li Q and Ling X: Camptothecin (CPT) and its derivatives are known to target topoisomerase I (Top1) as their mechanism of action: Did we miss something in CPT analogue molecular targets for treating human disease such as cancer? Am J Cancer Res 7: 2350-2394, 2017.
28. El-Khamisy SF, Hartsuiker E and Caldecott KW: TDP1 facilitates repair of ionizing radiation-induced DNA single-strand breaks. DNA Repair (Amst) 6: 1485-1495, 2007.

29. El-Khamisy SF, Saifi GM, Weinfeld M, Johansson F, Helleday T, Lupski JR and Caldecott KW: Defective DNA single-strand break repair in spinocerebellar ataxia with axonal neuropathy-1. Nature 434: 108-113, 2005.

30. Pommier Y, Barcelo JM, Rao VA, Sordet O, Jobson AG, Thibaut L, Miao ZH, Seiler JA, Zhang H, Marchand C, et al: Repair of topoisomerase I-mediated DNA damage. Prog Nucleic Acid Res Mol Biol 81: 179-229, 2006.

31. Feijoo C, Hall-Jackson C, Wu R, Jenkins D, Leitch J, Gilbert DM and Smythe C: Activation of mammalian Chk1 during DNA replication arrest: A role for Chk1 in the intra-S phase checkpoint monitoring replication origin firing. J Cell Biol 154: 913-923, 2001.

32. Zachos G, Rainey M and Gillespie DA: Lethal errors in checkpoint control-life without Chk1. Cell Cycle 2: 14-16, 2003.

33. Liu C, Zhou S, Begum S, Sidransky D, Westra WH, Brock M and Califano JA: Increased expression and activity of repair genes TDP1 and XPF in non-small cell lung cancer. Lung Cancer 55: 303-311, 2007.

34. Dean RA, Fam HK, An J, Choi K, Shimizu Y, Jones SJ, Boerkoel CF, Interthal $\mathrm{H}$ and Pfeifer TA: Identification of a putative Tdp1 inhibitor (CD00509) by in vitro and cell-based assays. J Biomol Screen 19: 1372-1382, 2014.

35. Pommier Y and Cushman M: The indenoisoquinoline noncamptothecin topoisomerase I inhibitors: Update and perspectives. Mol Cancer Ther 8: 1008-1014, 2009.

36. Zhang YW, Otterness DM, Chiang GG, Xie W, Liu YC, Mercurio F and Abraham RT: Genotoxic stress targets human Chk1 for degradation by the ubiquitin-proteasome pathway. Mol Cell 19: 607-618, 2005.

37. Walensky LD: BCL-2 in the crosshairs: Tipping the balance of life and death. Cell Death Differ 13: 1339-1350, 2006.

38. Tsukahara S, Yamamoto S, Tin-Tin-Win-Shwe, Ahmed S, Kunugita N, Arashidani K and Fujimaki H: Inhalation of low-level formaldehyde increases the $\mathrm{Bcl}-2 / \mathrm{Bax}$ expression ratio in the hippocampus of immunologically sensitized mice. Neuroimmunomodulation 13: 63-68, 2006.

39. Xu C, Xu W, Palmer AE and Reed JC: BI-1 regulates endoplasmic reticulum $\mathrm{Ca}_{2}{ }^{+}$homeostasis downstream of $\mathrm{Bcl}-2$ family proteins. J Biol Chem 283: 11477-11484, 2008.

40. Lo YL and Liu Y: Reversing multidrug resistance in Caco-2 by silencing MDR1, MRP1, MRP2, and BCL-2/BCL-xL using liposomal antisense oligonucleotides. PLoS One 9: e90180, 2014.

41. Liaud N, Horlbeck MA, Gilbert LA, Gjoni K, Weissman JS and Cate JHD: Cellular response to small molecules that selectively stall protein synthesis by the ribosome. PLoS Genet 15 : e1008057, 2019.

42. Watters DJ: Ascidian toxins with potential for drug development. Mar Drugs 16: 162, 2018.

43. Pavitt GD: Regulation of translation initiation factor eIF2B at the hub of the integrated stress response. Wiley Interdiscip Rev RNA 9: e1491, 2018

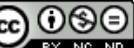

This work is licensed under a Creative Commons Attribution-NonCommercial-NoDerivatives 4.0 International (CC BY-NC-ND 4.0) License. 